\title{
INTERNATIONAL JOURNALOF
}

MULTIDISCIPLINARY STUDIES ON MANAGEMENT, BUSINESS, AND ECONOMY

Improving the performance of natural lighting in administrative buildings by using responsive parametric shading systems

Eng. Shaima Hassan Salam, a researcher at the Faculty of Engineering, Ain Shams University

Prof. Dr. Murad Abdel Qader, Professor of Architecture and Environmental Control, Ain Shams University

Prof. Hanan Mostafa Kamal Sabry, Professor of Architecture and Environmental Control, Ain Shams University

Prof. Hazem Talaat Al-Daly, Assistant Professor at the Faculty of Engineering, Ain Shams University

\section{: Research Summary}

Having natural lighting inside the building is one of the main strategies for saving energy and meeting the comfort requirements of users. Natural lighting design must be taken into account in the early stages of building design, as it is one of the most important decisions in this stage, and effective natural lighting design requires identifying several factors, including building orientation, sun path, design of envelopes, ceilings, and shading systems. The building envelope is the mediator between the interior and the exterior and thus greatly influences indoor climate, visual comfort and energy saving. Most of the restrictions affecting the building envelope change over time (weather condition - path of the sun. .(Climate change. User preferences. Noise - wind

Traditional building envelopes offer a single, stable solution that fits with all possible conditions and cannot adapt to changing conditions. Nevertheless, technological innovations are opening up towards the development of a generation of adaptive (climate-responsive) building envelopes that have the ability to maintain the best building performance configurations. On the changing conditions. Engineers and architects are beginning to experiment with adaptive envelope solutions to control solar radiation and natural lighting. The growing interest in adaptive systems that reconfigure themselves to meet changing climatic conditions and user needs has led to the conceptualization of multi-functional envelopes (responsive and dynamic, in order to increase the responsiveness of shading systems and to reduce systems that operate mechanically. The aim of this research is to improve the performance of natural lighting with Taking into account energy efficiency by examining and evaluating responsive external shading systems in administrative buildings .(located in the classified regional climate of Cairo, Egypt (hot, dry desert climate

\section{: Introduction}




\section{INTERNATIONAL JOURNALOF}

MULTIDISCIPLINARY STUDIES ON MANAGEMENT, BUSINESS, AND ECONOMY

Change in architecture is often associated with a change in ideas, materials and other elements related to the temporal eras of architectural applications, but we always find that a change in architectural design systems is a limited idea in architectural practices, although change is an important factor in architectural design systems because The cultural, environmental and technological context of architecture is in flux. In order to search for new solutions to link the external environmental conditions with the internal requirements of the buildings, the focus has begun on the design of building envelopes that gradually shift from being fixed to mobile covers, which not only improve environmental performance, but also save energy and in some applications, energy generation. Designers now have the tools to experiment with variable systems that use environmental factors to suit the needs and requirements of building users. Parametric design can propagate new standards in building .envelope design

Responsive casings are characterized by the ability to change some of their functions, shape, or behavior over time, repeatedly as responding to the changing environmental conditions surrounding the building and to meet the requirements of building users. Responsive packaging is considered one of the most promising strategies in modern techniques of architectural envelopes and it is receiving increasing attention from researchers and designers in architecture. Many different types of responsive packaging concepts have already been developed, and work is underway continuously to develop new technologies and concepts in this field. However, responsive packaging technology is not a well-defined and classified area of architectural research. For example, it is sometimes known as artificial intelligence or passive design, and sometimes it is represented by responsive facilities or .media covers

\section{:Research problem}

The use of traditional building envelopes does not help in improving natural lighting performance and visual comfort, as it does not adapt to changing weather conditions, and provides a single, stable solution to deal with a single climate situation. Therefore, there is a need to modernize the traditional approaches to building envelopes that act only as a passive barrier towards building envelopes that act as a responsive and adaptive separator .to the surrounding environment

\section{:Movable (responsive) building envelopes}

The design and orientation of building envelopes plays a critical role in the internal environmental quality of architectural spaces in administrative buildings. (Winther) suggests that "in order to create building envelopes that interact with the external environment, the microclimate of the building must be used" (Winther, 2012). Most of the elements of 


\section{INTERNATIONAL JOURNALOF}

MULTIDISCIPLINARY STUDIES ON MANAGEMENT, BUSINESS, AND ECONOMY

building envelopes are fixed (walls, ceilings, windows, materials) where the properties of walls and ceilings control the thermal resistance of internal spaces, while the properties of windows and transparent surfaces control the provision of natural lighting from both sides of the solar and optical transmission. This is in addition to the shading system, which is one of the elements of the building envelopes moving, and thus it can control the natural lighting and the optical and solar transmission in a positive way, more flexibility and effectiveness than the other elements of the building envelope, and the shading systems are controlled in several ways either by the user, or by By using the most flexible response technology

Building envelopes is a term used in building science and engineering and refers to building envelopes that relate to their changing environment in a dynamic way. There are many variable terms that are used in the field of mobile packaging such as "dynamic packaging", "adaptive packaging", "smart packaging", "cream packaging", and "responsive packaging". .Although the exact meaning of each term varies, they are often used interchangeably

\section{:Common Terms for Moving Covers}

Terminology related to animated shading systems is very broad. There is a clear tendency for research groups to define the vocabulary of each group to describe a specific type or approach to the mobile systems used in the field of research. Of the terms most commonly used are: (mobile systems, retractable systems, convertible systems, adaptive systems, dynamic systems, and responsive systems). These various terms are used to describe the interaction of functional shading systems with their environment or to describe the unstable nature of shading systems. In order to clarify the use of these terms, the authors and :researchers suggest some of the following general definitions

\section{:Moving systems}

They are systems subject to the study of the laws of motion, taking into account the forces and blocs involved in the movement, and emphasize the relationship between movement .and its causes

\section{:Retractable systems}

They are systems commonly used in the architecture of roofs with textile coverings in which the textile covering is either pulled or folded

\section{:Convertible systems}

It is one of the fluctuating ways in buildings to change from one shape to another according to different functions. It is possible to define two types of convertible systems: external convertibility, change or fluctuation of the building envelope, and internal convertibility, .related to internal spaces

\section{:Adaptive systems}




\section{INTERNATIONAL JOURNALOF}

MULTIDISCIPLINARY STUDIES ON MANAGEMENT, BUSINESS, AND ECONOMY

They are systems that have the ability to adapt and adjust to changing conditions on their own. Adaptive casings have the ability to change their behavior, properties, or .configurations in relation to external changes

\section{:Dynamic systems}

They are systems that study the forces acting on the body that lead to movement. The term is often used to designate building systems or envelopes that can be moved

\section{:Intelligent systems}

Intelligent systems use information technology to interconnect several independently operating subsystems (Brooks, 2011). Responsive systems: The term refers to reflex systems, i.e. a system that moves and is not subject to manipulation or internal operation, which means that the system moves and controls it from the outside through the environment interacting with the system, Hasselaar (2006. Nicholas Negroponte) defines the response as follows "Response means that the environment has an active role, and it begins with greater or lesser changes as a result of making complex or simple calculations." In this study we will specialize in responsive systems through which the building envelope can be linked to the external environment to work to improve visual comfort for users of administrative buildings

\section{:Responsive Shading Systems Concept}

Responsive shading systems are systems that analyze and interpret the changes that occur in the surrounding environment, then respond to these changes, and recent innovations in parametric architecture allow precisely controlled shading systems that interact with the various needs of buildings and users. This became possible through comprehensive research during the design stage, where all scenarios in which the system must work well are simulated, leading to the most efficient and best-performing scenario. These scenarios include different climatic conditions and special requirements for building users. Therefore responsive shading systems must provide adequate comfort at all times and conditions of .building users

Responsive shading systems have the ability to interact with their surroundings and are capable of adaptive behavior. In this case, the technology is not directly controlled by the user, but rather represents a change in itself to the environment surrounding the system, while responsive shading systems represent the extent to which the system can improve performance, not as a result of user interactions. This is a new phenomenon arising from the transformation of the system through a large number of variables. Through this transformation in systems, form became behavioral and movement captured the image in architecture. Although the term responsive systems can be synonymous with intelligent or interactive systems, responsive systems usually define envelope systems that in addition to sensor systems, actuators, and actuation mechanisms contain more complex response 
INTERNATIONAL JOURNALOF

MULTIDISCIPLINARY STUDIES ON MANAGEMENT, BUSINESS, AND ECONOMY

systems that "learn" and "reset" over time. . "Thus, responsive systems not only include sensor and actuator systems, but are also obligated to educate both the building and the .building users by means of reaction systems

The term "responsive architecture" was coined by Nicholas Negropont, for the first time in the late nineteenth century, when problems of spatial design were explored through the application of cybernetics to architecture. He suggested that responsive architecture is the natural product of integrating computing power into building structures and spaces, to obtain better performance buildings. The Responsive System measures actual environmental conditions (via sensors), then responding building elements can adapt through their shape, color, or behavior responsively (via motors). Its goal is to improve and expand an architecture system by improving the energy performance of buildings with responsive technologies. Responsive buildings (Meyboom et al. 2010) are defined as an ."architectural system that "causes change in its environment

The idea of responsive covers is based on the formation of multiple small units in the form of patterns that act as shading systems suspended on the facade and enable to block the sun's rays into the interior spaces or provide natural lighting and other functions that help the comfort of the building users, and it provides an infinite number of possibilities and solutions that It creates the ideal condition for effective natural lighting in different parts of the building according to the needs of each space. The units are arranged in a way that allows them to be transformed by rotating, folding, or closing and opening depending on the motors used and sensors. The introduction of parametric design tools in addition to the sensor and control systems contributed to providing the ability to implement an independent system where each unit of the casing works individually, by means of Respond .according to the data it receives from its sensor systems

\section{:Responsive Shading Systems Classification Approaches}

Designing and developing methodologies for classifying responsive systems began, and many efforts were made towards this. As the terminology is still not standardized, many classification approaches have been implemented by different projects of organizations and institutions specific to this field, some of them focus on specific design criteria, while others .try to follow a comprehensive approach to design concepts

\section{Sensors \& Detectors}

Sensors are the inputs into the operating system of responsive systems that give different information and data about the surrounding environment. They are devices with smart technologies, that sense environmental changes such as (solar radiation, pollution, noise ... etc.) and then collect the data, and give the system a signal to make the required changes according to the collected data, and be

\section{Contro unit}


INTERNATIONAL JOURNALOF

MULTIDISCIPLINARY STUDIES ON MANAGEMENT, BUSINESS, AND ECONOMY

ISSN: $2735-5446$

VOLUME 2, ISSUE 2, 2019, $29-39$.

The process control unit is represented in the process responsible for making the movement decision and thus receives information from the input systems and transmits it to the :motors that move the structure. There are three types of control systems as follows

\section{:Internal control}

Where the control system is divided into several systems, priority is given to the system that makes the decision without an external control unit

\section{External control}

Where the system has the ability to make the decision either on its own or from some other .source outside, such as items that can be moved by manual control

\section{:Complex systein}

It is a system that integrates the two previous systems where a decision can be made either by self or by using inputs. It is classified into four types: (Direct Control, Indirect Control, .(Indirect Control by Multi-Input, Indirect Control, Intelligent

\section{Motors: actuators}

Motors are devices that move the system through the power source, in other words they are the devices responsible for changing the moving element according to the orders issued by the operations of the control unit, and often the power source is electric or pressuredependent motors such as hydraulic pistons where you compress liquids That results in .(movement and there are two types of engines: (traditional motors, smart materials

As for smart materials, Stimulus - Responsive Materials / SRMS materials are often used in solar shading systems, as they help to relate the building envelope to the surrounding environmental changes and treat these changes as catalysts (Figure 5). And that by changing its physical or chemical properties. The stimulus response materials are divided into two main types: Shape Change Materials / SCMs, which are materials that are able to change their shape when the correct stimulus is present, and Shape Memory Materials / SMIMs, which are used with all materials that are capable. On the change and retention of the changed form, where the resulting change from the stimuli takes place and then the shape is restored again in the absence of these stimuli (Figure 6). Usually, these substances are activated by a difference in temperature or sound frequencies, and there are three types of materials that remember the shape: Shape Memory Hybrids SMHs /, Shape Meinory Alloys / SMIAs, Polymer Shape SMPs. In one study conducted by (Fiorito E, 2016), the properties of the three types of shape-remembering materials that are used in responsive shading systems were compared. The comparison showed that a shape-remembering polymer is the most effective material, given the fact that the rate of shape change is higher than that of a 


\section{INTERNATIONAL JOURNALOF}

MULTIDISCIPLINARY STUDIES ON MANAGEMENT, BUSINESS, AND ECONOMY

substance. A metal that remembered the shape by $10 \%$, and also higher than a hybrid material that remembered the shape by $8-6 \%$, however, at the present time, a metal material that remembered the shape is the most used type because it is able to exceed 200,000 cycles, while a polymer material that remembered the shape was tested and (reached Up to 200 cycles only, and no shaped hybrids were subjected to any tests. (11

\section{:Control system}

A control system is a device or group of devices that manage, direct, or regulate the behavior of a system or several systems. And the control system consists of three elements: the input, which represents the information and data coming from the sensors, the Controller unit, and the Output, which represents the motors that carry out the change process resulting from the response, although the term responsive systems It may be synonymous with intelligent or interactive systems, except that responsive systems usually define shell systems that in addition to sensor systems, actuators, and actuation mechanisms contain more complex response systems that "learn" and "reset" over time, and therefore, responsive systems do not include Not only sensing systems and motors, but also committed to educating both the building and the building users through Feedback .(Systems. (Figure 7

\section{:Responsive shading systems evaluation criteria}

According to the scientific plan made by Cooperation in Science and Technology

European (COST), in order to evaluate and test the performance of responsive shading systems, I found that the system must be described in terms of several criteria, the most important of these criteria are: the response element, response factors, response objective, response effect, response time, and movement type, and the following are: Definitions of .Responsive Scattering Systems Standards

\section{:The response component}

In buildings, there are a number of elements that can be adapted, and the element is chosen based on the response factor. The response elements are divided under four main headings: (shading systems, ceilings, walls, materials). They are not divided into sub-categories, and in .this study we specialize in the component of shading systems

\section{:Response factors}

It is the reason for the change in the response element, so the system can respond to the environment or the user or things in the responsive shading systems. The response factor is the environment and there are two main types of response factors for solar shading 
systems, first: - Response factors to the internal environment are temperature, lighting Natural, humidity, and internal ventilation, and secondly: - the response factors to the external environment, represented in solar radiation, natural lighting, humidity, and wind .((2010, Schnadelbach

\section{:Response Objective}

It is represented in the purpose on which the system is based, and the goals of the response can be divided into four goals: thermal comfort, visual comfort, auditory comfort, and energy saving. Motion or matter, and in responsive shading systems, the effect of change is often in shape and motion

\section{:Response Time}

Responsive systems use time to transform themselves or to change their properties (Fernandez, 2014). Response time refers to the time scale in which the process occurs. Change in effectiveness. This time range varies from very short periods (seconds to very long periods (several years), in shading systems it determines a response time either by the hour, by the day, or by season. "Movement type: determines the pattern of movement. According to the local displacement, movement occurs mainly in three ways, which are partial change or complete change or a combination of them. Examples of movement that have been .applied in solar shading systems are rotation, folding, closing and opening

\section{:Findings and recommendations}

The response shows a general concept for protecting systems from sudden surrounding changes and responsive shading systems show the importance of this concept in practical application to buildings, which confirms its importance in addressing environmental problems in existing administrative buildings, and remedying its presence in newly constructed buildings, and it is worth noting that responsive systems are related to sustainability. As a general concept, and contribute to raising efficiency and performance in buildings, the following are the most important results that were reached through this .research

\section{: Results}

In this research, the evaluation of the performance of responsive shading systems in terms of improving natural lighting in administrative buildings is discussed in two parts. The first part is a review of the classification of responsive shading systems, although there are several ways to classify the responsive shading systems approaches that have been clarified in many studies. And previous researches that have been clarified in this chapter, however, this parchment can be summarized into a combined classification by focusing on the most important points that affect the choice of an appropriate responsive shading system 


\section{INTERNATIONAL JOURNALOF}

MULTIDISCIPLINARY STUDIES ON MANAGEMENT, BUSINESS, AND ECONOMY

The method of parametric origami design has also been recognized and its characteristics and characteristics affecting the design process have been identified. Responsive shading systems, as they are considered one of the most important modern technologies for .responsive shading systems that receive a lot of attention in architectural design

As for the second part of this chapter, the performance of natural lighting and the responsive shading systems were analyzed in three case studies in three cities characterized by a hot dry desert climate (BWH), such as the region of Cairo, Egypt ,,,). The analytical study showed in the first case study (Abraj Al-Bahhar / Abu Dhabi, United Arab Emirates) that the saturated shade systems achieved a reduction in cooling loads by up to $25 \%$, a reduction in solar heat gains by up to $20 \%$ to $50 \%$, and the provision of natural lighting. Useful Daylight Illuminance UDI value ranges between 250 to 2000 lux. The second case study (Spa Building / Riyadh / Saudi Arabia) showed that responsive shading systems achieved a reduction in cooling loads by $15-20 \%$, and the shading system He provided natural diffused and reflected lighting through the holes and layers on the surface of the envelope that make up the mosaic formations, and the third case study (Burton Barr Central Library Building, Phoenix / USA) showed the importance of designing solar shading systems for the building separately for each facade according to the direction, and how it was found A system that fits every direction helps create natural lighting in all spaces

\section{:Recommendations}

Through the existing theoretical and analytical study in this research, the following is :recommended

The necessity to reach a definition of the standards and approaches of the shading -1 systems organization that are claimed by specialized bodies and organizations, and to make them standard standards for all designers and architects so that the field of responsive shading systems becomes an identifiable and specific field in architecture

Spreading and educating designers and architects in Egypt of the importance of -2 responsive shading systems, and working on providing the resources and skills necessary to .apply these systems in buildings

Carrying out studies that determine the cost of these systems and the possibility of their -3 incorporation into buildings without the need for an increase in the cost imposed in traditional construction

\section{:References}

\section{:Foreign references}


1- Aelenei, D., Aelenei, L., \& Vieira, C. P. (2016). Adaptive Façade: concept, applications, research questions. Energy Procedia, 91, PP 269-275.

2- Al Dakheel, J., \& Tabet Aoul, K. (2017). Building Applications, Opportunities and Challenges of Active Shading Systems: A Stateof-the-Art Review. Energies, 10(10), PP 1672.

3- Attia, S. (2017). Evaluation of adaptive facades: The case study of Al Bahr Towers in the UAE. QScience Connect, 2017(2),PP 6.

4- Barozzi, M., Lienhard, J., Zanelli, A., \& Monticelli, C. (2016). The sustainability of adaptive envelopes: developments of kinetic architecture. Procedia Engineering, 155,PP 275-284.

5- BASARIR, B., \& ALTUN, M. C. A Classification Approach for Adaptive Façades.

6- Braybrook, P. (2004). U.S. Patent Application No. 10/671,PP 828.

7- Crawford, S. (2010). A breathing building skin. In Proceedings of the 30th annual conference of the Association of Computer Aided Design in Architecture ACADIA (pp. 211-217).

8- El Daly, H. M. T. (2004). Architecture in the age of information technology, PHD, Ain Shams University.

9- Elghazi, Y., Wagdy, A., Mohamed, S., \& Hassan, A. (2014). Daylighting driven design: optimizing kaleidocycle facade for hot arid climate. In Aachen: Fifth German-Austrian IBPSA Conference, RWTH Aachen University.

10- Elkhayat, Y. O. (2014). Interactive movement in kinetic architecture. Engineering Sciences, 42(2), PP 816-845.

11- Fiorito, F., Sauchelli, M., Arroyo, D., Pesenti, M., Imperadori, M., Masera, G., \& Ranzi, G. (2016). Shape morphing solar shadings: A review. Renewable and Sustainable Energy Reviews, 55, PP 863 884.

12- Grijalva, K. (2012). Associative Design for Building Envelopes' Sun Control and Shading Devices. Arizona State University.

13- Gunderson, R. D. (2015). RESPONSIVE BUILDING ENVELOPES PHD, Carleton University Ottawa. 
14- HARRY, S. (2016). Dynamic Adaptive Building Envelopes-an Innovative and State-of The-Art Technology.

15- Loonen, R. C., Trčka, M., Cóstola, D., \& Hensen, J. L. M. (2013). Climate adaptive building shells: State-of-the-art and future challenges. Renewable and Sustainable Energy Reviews, 25, PP 483-493.

16- Tashakori, M. (2014). Design of a computer controlled suntracking facade model.

17- Verma, S., \& Devadass, P. (2013). Adaptive [skins]: Responsive building skin systems based on tensegrity principles.

18- Wigginton, M., \& Harris, J. (2013). Intelligent skins. Routledge.

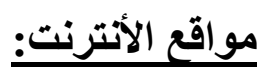

19- https://advancedtextilessource.com/2013/10/08/responsivetextiles-vs-reactive-facadesystems/Accessed March 2018.

20- http://noizear.com/database-of-adaptive-structures/index.html/ Accessed April 2018.

21- http://koeppen-geiger.vu-wien.ac.at/ Accessed March 2018.

22- https://content.iospress.com/articles/journal-of-facade-design-and engineering/fde0040/Accessed April 2018.

23- https://inhabitat.com/chuck-hoberman-designs-kinetic-buildingcanopy-to-filter-sunlightin-riyadh/ Accessed March 2018.

24- http://sah-archipedia.org/buildings/AZ-01-013-0014/ Accessed March 2018. 